\title{
O PROCESSO DE INTEGRAÇÃO SUL-AMERICANA A PARTIR DA COMUNIDADE SUL-AMERICANA DE NAÇÕES
}

\section{Gabriel Jamur Gomes}

Acadêmico do quinto ano diurno da Faculdade de Direito da Universidade Federal do Paraná.

RESUMO: A criação da Comunidade Sul-Americana de Nações, em 9 de dezembro de 2004, ao final da III Reunião de Presidentes da América do Sul, na cidade de Cuzco no Peru, é resultado da soma dos processos de integração da Comunidade Andina de Nações (CAN) e do Mercosul - reunindo dez países sul-americanos, mais Suriname e Guiana - com um Produto Interno Bruto acumulado de aproximadamente um trilhão de dólares. Esse projeto pode ser uma alternativa à uma integração imperialista feita pela América do Norte por via da ALCA (Área de Livre Comércio das Américas). Portanto, tal integração corresponde à consubstanciação dos sonhos inacabados de Bolívar e San Martín por uma efetiva união sul-americana. 
"Não há de ser a General Motors ou a IBM que terá a gentileza de levantar, no nosso lugar, as velhas bandeiras de unidade e emancipação (latino-americanas) caídas na luta."

Eduardo GALEANO, As veias abertas da América Latina

\section{INTRODUÇÃO: A COMUNIDADE SUL-AMERICANA DE NAÇÕES}

A criação da Comunidade Sul Americana de Nações - foco essencial de estudo no presente trabalho -, em 09 de dezembro de 2004, ao final da III Reunião de Presidentes da América do Sul, na cidade de Cuzco no Peru, é resultado da soma dos processos de integração da Comunidade Andina de Nações (CAN) e do Mercosul reunindo, desta forma, dez países sul-americanos, mais Suriname e Guiana - com um Produto Interno Bruto acumulado de aproximadamente um trilhão de dólares. Esse projeto pode ser uma alternativa à uma integração imperialista feita pela América do Norte via ALCA (Área de Livre Comércio das Américas). Desta forma, tal integração corresponde à consubstanciação dos sonhos inacabados de Bolívar e San Martín por uma efetiva união sul-americana. A importância, tanto simbólica quanto histórica destes fatos é explicitada pela própria Declaração de Cuzco:

Os Presidentes dos países da América do Sul, reunidos na cidade de Cuzco, por ocasião da celebração das façanhas libertadoras de Junín e Ayacucho e da convocação do Congresso Anfictiônico do Panamá, seguindo o exemplo do Libertador Simón Bolívar, do Grande Marechal de Ayacucho, Antonio José de Sucre, do Libertador José de San Martín, de nossos povos e heróis independentistas que construíram, sem fronteiras, a grande Pátria Americana e interpretando as aspirações e anseios de seus povos a favor da integração, unidade e construção de um futuro comum, decidimos formar a Comunidade Sul-americana de Nações. ${ }^{1}$

Conforme ressalta o Secretário Geral da Comunidade Andina, a Comunidade Sul-Americana de nações será, considerado seu PIB, a quinta maior potência mundial, a quarta em população - com 360 milhões de habitantes (67 \% da população da América Latina) - e possuirá um território de 17 milhões de km2, com

1 MRE. Declaração de Cuzco sobre a Comunidade Sul-Americana de Nações. Disponível em: <http://www.mre.gov.br>. Acesso em 10 maio. 2005. 
enorme potencial de riquezas em recursos minerais e biodiversidade ${ }^{2}$ desta forma, será o terceiro maior bloco do mundo, ficando atrás apenas da UE e do NAFTA.

Este processo de integração comunitária sul-americana estará sustentado por três pilares básicos, que são: I. cooperação política, social e cultural - ações conjuntas nas áreas de segurança, fortalecimento da democracia, políticas culturais conjuntas, cooperação regional em projetos de inclusão social e desenvolvimento sustentado etc.; II. integração econômica, comercial e financeira - numa perspectiva já apresentada pela ACE 59 do XIII Conselho de Ministros da ALADI (18/10/2004); III. desenvolvimento da infraestrutura física, energética e de telecomunicações através da IIRSA - com o destaque para dez grandes projetos-chave para a consecução desta meta, além de uma carteira de trezentos e trinta e cinco a serem desenvolvidos nos próximos trinta anos e trinta e um a serem executados nos próximos cinco anos.

A integração ocorrerá de maneira gradual a partir da compatibilização e convergência dos instrumentos econômicos, políticos e jurídicos da Comunidade Andina de Nações e do Mercado Comum do Cone Sul, além da definição de calendários de trabalhos em conjunto, com o aproveitamento dos organismos regionais já existentes - como ALADI, OTCA, SELA, a fim de acelerar o processo de integração. Tal processo, contudo, busca ir além de um tratado de livre comércio, tendo como meta uma real integração sul-americana, tanto no seu aspecto econômico, quanto nos seus aspectos sociais e institucionais. Como primeira etapa desta construção, está marcada para o segundo semestre de 2005 a Primeira Reunião dos Chefes de Estado da Comunidade Sul-Americana de Nações a ser realizada no Brasil, sendo a presidência pro tempore do Peru.

Contudo, o projeto é visto pela comunidade internacional com um certo ceticismo em relação ao seu sucesso, principalmente quanto à debilidade das bases econômicas comuns dos países envolvidos. Além disso, há de se levar em consideração a resistência dos países envolvidos ao papel hegemônico que o Brasil pode assumir (e provavelmente assumirá) no bloco, em razão do porte de sua economia.

2 WAGNER, Allan. "La Comunidad Sudamericana de Naciones: Un gran programa de desarrollo descentralizado". Disponível em: <http://www.comunidadeandina.org>. Acesso em 10 mar. 2005. 
Para uma apresentação minudenciada do projeto da Comunidade, serão objetos de análise no presente trabalho: seus antecedente históricos; uma avaliação do Plano de Ação para a Integração da Infra-Estrutura Regional Sul-Americana (IIRSA); o Acordo de Complementação Econômica (ACE) N. 59, e o próprio documento - Declaração de Cuzco sobre a Comunidade Sul-Americana de Nações - com benesses e dificuldades que o envolvem.

\section{ANTECEDENTES HISTÓRICOS}

Neste trabalho serão analisados apenas os antecedentes recentes do processo para a criação da Comunidade Sul-Americana de Nações, pois uma análise mais profunda da integração social, cultural e política sul-americana remontaria a todo o processo de colonização do subcontinente e fugiria do escopo principal do estudo. Da mesma forma, não serão objetos de análise os marcos de integração do Mercosul, uma vez que estes já foram exaustivamente analisados em obras anteriores. Desta forma, o processo em questão, numa perspectiva brasileira, advém de 1993 quando foi proposta pelo Itamaraty, como contraponto sul-americano ao surgimento do NAFTA (Área de Livre Comércio da América do Norte), a criação de uma Área de Livre Comércio Sul-Americana (ALCSA) como desdobramento do projeto de Iniciativa Amazônica de 1992 - que pretendia estabelecer uma área de livre comércio entre os países abrangidos pelo Tratado de Cooperação Amazônica de 1978. A aposta brasileira num fortalecimento do Mercosul durante os anos seguintes da década de 1990, sofreu um grande abalo com as crises econômicas que ocorreram ao final da década, em função das políticas neoliberais de câmbio e de reforma do Estado adotadas pela maioria dos países sul-americanos no período - possuindo maior relevo as crises brasileira e Argentina. ${ }^{3}$

A fim de encontrar meios conjuntos de proteção frente ao processo de globalização que originou tais crises, são retomados pelos países sul-americanos 
diálogos para a sua integração regional, culminando com a I Reunião de Presidentes da América do Sul, em Brasília no ano de 2001 - convocada pelo Brasil e também conhecida como a I Cúpula Sul Americana. Os resultados deste encontro foram expressos no documento denominado "Comunicado de Brasília", que estabelecia entre os seus objetivos essenciais, a integração regional com o fim de criar um mercado de livre comércio na América do Sul - artigo 8o do Comunicado de Brasília. Tal integração - fundada num modelo de regionalismo aberto - objetiva duas metas: (i) uma integração econômica consubstanciada por uma aproximação da CAN e do Mercosul e pela inclusão do Chile, Guianas e Suriname; (ii) a formação de uma infra-estrutura de integração, proposta através do "Plano de Ação para a Integração da Infra-Estrutura Regional Sul-Americana" (IIRSA) - artigo 39 e Anexo I do Comunicado -, nas áreas de transportes, energia e telecomunicações.

Os esforços de 2001 na integração sul-americana foram reafirmados e aprofundados por ocasião II Reunião de Presidentes da América do Sul em 2002 que ocorreu na cidade equatoriana de Guayaquil. Esse encontro, além de reafirmar os objetivos estabelecidos em Brasília - principalmente no tocante à IIRSA -, estabeleceu a criação de uma área de segurança na região através da adoção da Declaração da Zona de Paz Sul-Americana - artigo 3 e Anexo II do "Consenso de Guaiaquil Sobre Integração, Segurança e Infra-Estrutura para o Desenvolvimento".

Paralelamente aos encontros da cúpula, o Mercosul e a Comunidade Andina negociam desde 1995, no âmbito da Associação Latino-Americana de Integração (ALADI), uma zona de livre comércio entre os dois blocos. Em 1998 é assinado o acordo-quadro em Buenos Aires como marco inicial para o estabelecimento da zona, prevendo a criação desta em duas etapas: (i) até 1998 seria firmado um Acordo de Preferências Alfandegárias; (ii) e até 1999 seria negociada a zona de livre comércio que entraria em vigor a partir de 2000. No entanto, as negociações para o Mercosul

\footnotetext{
3 "La crisis brasileña de 1998, aunque muy importante, no tuvo resultados desastrosos para el propio Brasil, pero provocó la caída de la Argentina y del Uruguay, al quebrar el modelo regional del ancla cambiaria, e inauguró un ciclo de empobrecimiento muy marcado, que se está procesando y del cual el Brasil no ha salido indemne. La crisis, como no podía ser de otro modo, invalidó los efectos limitados, pero benéficos, del MERCOSUR durante los años 90 y minó su relativa credibilidad. La asociación comercial lejos de producir efectos anticíclicos, actuó como agente transmisor de la crisis al reducir drásticamente el comercio recíproco, como consecuencia de las manipulaciones monetarias, la guerra comercial y la ausencia de "affectio societatis", ausencia que se tradujo por la falta de un mínimo de solidaridad y acción concertada en beneficio de los intereses comunes, demostrada por sus miembros." GINESTA, Jacques. Los sistemas de integración a comienzos del siglo XXI. Disponível em: http://www.amersur.org.ar. Acesso em 13 de maio. de 2005.
} 
não ocorrem satisfatoriamente e são negociadas bilateralmente em três blocos separados de países: Brasil com a CAN - assinado em 1999; Argentina com a CAN - assinado em 2000; Uruguai e Paraguai com a CAN. Em 2001 as negociações são retomadas em Assunção para a concreção da zona de livre comércio entre os dois blocos e o Chile. Os debates seguem até 2003, quando as partes assinam o acordo que estabelece a zona de livre comércio, e por fim, em outubro de 2004, por ocasião da XIII Reunião do Conselho de Ministros da ALADI, em Montevidéu, é depositado o Acordo de Complementação Econômica (ACE) № 59 para a conformação de uma Zona de Livre Comércio entre o Mercosul e a CAN.

Por fim, em 09 de dezembro de 2004, ocorre a III Reunião de Presidentes da América do Sul, na cidade de Cuzco no Peru, e os avanços conquistados no processo de integração sul-americana são consubstanciados na Declaração de Cusco sobre a Comunidade Sul-Americana de Nações e na Declaração de Ayacucho, ficando estabelecido o marco fundamental da Comunidade SulAmericana de Nações. Desta forma, ficam claros os dois elementos fundamentais da mesma - que serão nosso objeto seguinte de análise: a IIRSA e o ACE N. 59.

\section{O PLANO DE AÇÃO PARA A INTEGRAÇÃO DA INFRA-ESTRUTURA REGIONAL SUL-AMERICANA (IIRSA) COMO ELEMENTO ESSENCIAL À INTEGRAÇÃO}

A IIRSA, conforme acima exposto, é estabelecida na I Reunião de Presidentes da América do Sul na cidade de Brasília em 2001, e possui como texto base, o "Comunicado de Brasília" e seu Anexo I. Seu fundamento é que um real processo de integração regional sul-americana será possível apenas se vier acompanhado de uma integração da infra-estrutura energética, de transportes e telecomunicações do subcontinente ${ }^{4}$ :

"Integração e desenvolvimento da infra-estrutura física são duas linhas de ação que se complementam. A formação do espaço econômico ampliado sul-americano almejado pelas

4 "Sudamérica solo podrá crecer de manera sostenida si incrementa su competitividad. Se trata de una región emergente con gran potencial de desarrollo y atractivo para las inversiones internacionales por su dotación de recursos, los procesos de integración regional en vigencia, sus sistemas democráticos. Para que ese potencial se realice, para lograr una inserción competitiva en el mundo, para aprovechar la potencialidades de la complementariedad regional, para todo ello, la infraestructura es central. Hay que revertir los déficit en la extensión y calidad de la infraestructura." GADEA, Rosario Santa. La Iniciativa IIRSA - El Reto de Integrar el Espacio Físico de América del Sur. Disponível em: <http://www.comunidadeandina.org>. Acesso em 10 mar. 2005. 
sociedades da região dependerá da complementação e expansão de projetos existentes e da identificação de novos projetos de infra-estrutura de integração, orientados por princípios de sustentabilidade social e ambiental, com capacidade de atração de capitais extraregionais e de geração de efeitos multiplicadores intra-regionais. Avanços no campo da infra-estrutura, por sua vez, reverterão em novos impulsos para a integração, criando-se assim uma dinâmica que deve ser incentivada. Esse cenário seria ainda beneficiado por uma política de investimentos com perspectiva regional e não apenas nacional."

O projeto consiste em Dez Eixos de Integração e Desenvolvimento ${ }^{6}$ entre os países signatários, Sete Processos Setoriais de Integração e uma carteira de trezentos e trinta e cinco projetos a serem avaliados em relação ao seu impacto para a viabilização do funcionamento dos eixos de integração, e que representarão um volume de gastos na ordem de 37 bilhões de dólares no continente sul-americano para o qüinqüênio 2005-2010 está previstos o investimento de 4 bilhões de dólares numa "agenda de implementação consensuada" de trinta e um projetos selecionados por terem sido considerados essenciais para a integração física do continente.

Essa iniciativa de modernização e implementação de um infra-estrutura regional há de ser financiada pelos governos, por parcerias com a sociedade civil nas formas de Parceria Público-Privadas (PPP's) - e pelas seguintes agências multilaterais de fomento - artigo 38 do Comunicado: o Banco Interamericano de Desenvolvimento - que desenvolveu o plano de ação; a Corporação Andina de Fomento; o Fundo Financeiro para o Desenvolvimento da Bacia do Prata e o Banco Mundial - no Brasil, o BNDES será uma das instituições financeiras fundamentais de financiamento do Plano. ${ }^{7}$

Os Processos Setoriais de Integração da IIRSA pretendem realizar ações de integração que abarquem os setores que figuram como um entrave nas relações

\footnotetext{
${ }^{5}$ Art. 37 do "Comunicado de Brasília".

${ }^{6}$ 1. Eixo Andino. 2. Eixo Andino do Sul. 3. Eixo de Capricórnio. 4. Eixo da Hidrovia Paraguai-Paraná. 5. Eixo Multimodal del Amazonas. 6. Eixo do Escudo Guianense. 7. Eixo do Sul. 8. Eixo Interoceânico Central. 9. Eixo Mercosul-Chile. 10. Eixo Peru-Brasil-Bolívia.
} 
entre os países e que inibem o comércio por sua deficiência em infra-estrutura: (a) Instrumentos para o Financiamento de Projetos; (b) Mercados Energéticos Regionais; (c) Passagens de Fronteira; (d) Sistemas Operativos de Transporte Aéreo; (e) Sistemas de Operativos de Transporte Marítimo; (f) Sistemas de Operativos de Transporte Multimodal; (h) Tecnologia, Informações e Telecomunicações.

Por sua vez, tais processos terão como base a construção de eixos de integração e desenvolvimento, que funcionarão como meios de superação dos obstáculos naturais do subcontinente - Amazônia, Andes, Pantanal etc. - e espaços-guia para a integração comercial ${ }^{8}$. Entretanto, é necessário ressaltar que a integração envolve aspectos mais profundos de desenvolvimento do que a mera existência de uma infra-estrutura física. Desta forma, ela deve vir acompanhada de ações e programas que viabilizem o desenvolvimento social e econômico das regiões envolvidas. ${ }^{9}$

Não obstante, ante à magnitude do projeto e das obras que servirão para que as metas estabelecidas sejam alcançadas, ele é alvo de várias críticas por parte da sociedade civil. Principalmente em relação aos impactos ambientais em zonas de rica biodiversidade e fragilidade, tais como a Amazônia e o Pantanal. ${ }^{10}$

7 "A IIRSA está fundamentalmente voltada ao atendimento das demandas do mercado externo, da produção e comercialização de mercadorias de grande aceitação no mercado internacional. Por necessitar de grande quantidade de capital para ser implementada, a IIRSA traz em seu bojo toda uma rede de mecanismos para atrair a iniciativa privada para participar de todas as fases da estratégia, desde a concepção dos projetos até a posterior gestão dos empreendimentos. Não obstante, a integração física prevista pela IIRSA será insuficiente para alavancar o comércio intra-regional, de acordo com os seus formuladores e/ou apoiadores, se os Estados Nacionais não negociarem e firmarem acordos para compatibilizar suas legislações e regras aduaneiras, resolverem problemas fronteiriços etc. Além disso, é necessário que cada país tome a iniciativa para melhorar e ampliar sua própria infra-estrutura física." CARVALHO, Guilherme. A estratégia de integração da infra-estrutura da América do Sul e o Governo Brasileiro. Disponível em: www.fase.org.br. Acesso em: 20 de maio. de 2005.

8 "En la Iniciativa IIRSA se han identificado los dos Ejes consolidados actualmente existentes en Sudamerica que son base de mercados subregionales en el marco de esquemas de integración: el Eje Andino (entre los cinco países de la Comunidad Andina-CAN) y el Eje Mercosur-Chile. Junto a los Ejes consolidados están los Ejes "transversales" que articulan países tanto de la Comunidad Andina como del Mercosur. La mayoría de estos Ejes son espacios emergentes por construir. Ellos son: al norte, el Eje Escudo Guyanés (Venezuela, Brasil, Guyana y Surinam); en el centro, el Eje del Amazonas (Colombia, Ecuador, Perú, Brasil), el Eje Perú-Brasil-Bolivia; en el centro-sur, el Eje Interoceanico Central (Perú, Chile, Bolivia, Paraguay, Brasil), el Eje Capricornio (Bolivia, Argentina, Paraguay, Brasil), el Eje Hidrovía Paraguay-Paraná (Bolivia, Paraguay, Argentina, Brasil); al sur, el Eje del Sur (Argentina-Brasil)." GADEA, Rosario Santa. La Iniciativa IIRSA - EI Reto de Integrar el Espacio Físico de América del Sur. Disponível em: <http://www.comunidadeandina.org>. Acesso em 10 mar. 2005.

${ }^{9}$ GADEA, Rosario Santa. La Iniciativa IIRSA - El Reto de Integrar el Espacio Físico de América del Sur. Disponível em: <http://www.comunidadeandina.org>. Acesso em 10 mar. 2005.

10 "Os grandes projetos planejados para a Amazônia trarão grandes impactos sócio-ambientais irreversíveis para essas regiões, como inundação de extensas áreas de floresta, aumento da produção de soja que ocasionará conversão de florestas em plantações e expulsão de agricultores familiares." PAIM, Elisangela Soldatelli. Projeto milionário pode trazer graves prejuízos ambientais. Disponível em: < http://www.comciencia.br>. Acesso em 10 mar. 2005. 
Desta forma, a IIRSA é considerada uma das pedras angulares do processo de criação da Comunidade Sul-Americana de Nações - sendo ela aludida em todos os documentos constitutivos da Comunidade, pois para a entrada em vigor da mesma, será necessária a integração infra-estrutural da região.

\section{ACORDO DE COMPLEMENTAÇÃO ECONÔMICA (ACE) N. 59 PARA A CONFORMAÇÃo DE UMA ZONA DE LIVRE COMÉRCIO ENTRE $O$ MERCOSUL E A CAN.}

Fruto de mais de nove anos de negociações, o ACE n. .59 foi depositado na ALADI em 2004, firmando a Área de Livre Comércio entre os blocos do Mercosul e da Comunidade Andina. O processo de elaboração do acordo encontrou inúmeros percalços pelo caminho, principalmente diante das dificuldades encontradas em relação ao "ritmo e prazo de desagravação, a quantidade de produtos sensíveis, regras de origem, mecanismo de solução de controvérsias e a área agrícola, o setor mais sensível para os países andinos". ${ }^{11}$ As negociações giraram em torno da não exigência, por parte do Mercosul, em relação às áreas de área de agricultura e em regras de origem, e da exigência contrapartida da CAN na redução da lista de produtos sensíveis e prazos de desagravação. ${ }^{12}$ Contudo, foram encontradas grandes dificuldades nas reuniões de trabalho para a formação do acordo nos prazos estipulados, o que acabou por gerar vários acordos bilaterais e exceções impossibilitando, assim, a entrada em vigor do texto final no prazo previsto $\left(1^{\circ} \stackrel{\text { de }}{ }\right.$ Julho de 2004).

O acordo em si objetiva principalmente o estabelecimento de um "marco jurídico e institucional de cooperação e integração econômica e física que contribua para a criação de um espaço econômico ampliado que vise a facilitar a livre

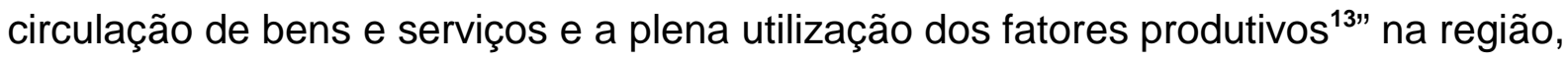
formando uma área de livre-comércio sem "restrições tarifárias e não-tarifárias que afetam o comércio recíproco".

${ }^{11}$ PAIVA, Paulo. Mercosul e andinos discutem acordo no começo de Outubro. Gazeta Mercantil, 12 de set. de 2002, p. A12.

12 PAIVA, Paulo. Mercosul e andinos discutem acordo no começo de Outubro. Gazeta Mercantil, 12 de set. de 2002, p. A12.

${ }^{13}$ Artigo $1^{\circ}$ do ACE n. $\div 59$. 
O acordo prevê um programa de liberalização comercial com a eliminação progressiva de barreiras alfandegárias num prazo máximo de 15 anos - com prazos diferenciados para produtos sensíveis das economias menores, Equador e Paraguai. Da mesma forma, as regras sobre regime de origem são diferenciadas para as economias menos desenvolvidas.

As salvaguardas tendem a ser eliminadas ao longo do processo de desagravação e um período adicional de 4 anos. Foram estabelecidos dois regimes de solução de controvérsias: um transitório, com três instâncias - Consultas Recíprocas e Negociações Diretas, Intervenção da Comissão Administradora e Grupo de Experts; e um definitivo, que será incorporado ao acordo com um protocolo adicional e possui três instâncias também - Negociações Diretas, Intervenção da Comissão Administradora e Procedimento Arbitral.

O acordo trata ainda de Medidas Antidumping e Compensatórias; Práticas Restritivas de Livre Concorrência; Aplicação e Utilização de Subsídios; Normas, Regulamentos Técnicos e Avaliação de Conformidade; Medidas Sanitárias e Fitosanitárias; Medidas Especiais; e Propriedade Intelectual. Há também, em coadunação com a IIRSA, uma preocupação presente em relação à formação de uma infra-estrutura regional entre os blocos.

A seriedade do acordo é questionada pela crítica, principalmente no tocante à prioridade que a Comunidade Andina dá ao seu maior parceiro comercial: os EUA. O que acaba por gerar uma negociação da CAN em relação à ALCA desvinculada do Mercosul. ${ }^{14}$

De qualquer forma, essa integração econômico-comercial entre o Cone Sul e a Comunidade Andina, será o segundo marco fundamental na integração sulamericana através sistema proposto na Declaração de Cuzco. E balizará os passos seguintes do processo integracional em conjunto com a IIRSA.

14 "'Esta será', segundo um comunicado no site da CAN, 'a principal ferramenta para geração de empregos, maior atração de investimentos e um desenvolvimento tecnológico mais dinâmico.' O comunicado é perfeitamente explícito quanto à importância atribuída ao acordo com os Estados Unidos, principal parceiro comercial dos três países. Qualquer semelhança entre a política de Toledo e a estratégia do governo brasileiro, portanto, é apenas aparente. É altamente improvável que a semelhança se torne real a partir de um acordo de comércio de efeitos por enquanto difíceis de avaliar." O Estado de SP. Editorial: Acordo Mercosul-CAN. Disponível em: http://www.estadao.com.br. Acesso em 15 de maio. de 2005. 


\section{A DECLARAÇÃO DE CUZCO E O ESTABELECIMENTO DA COMUNIDADE SUL-AMERICANA DE NAÇÕES}

Conforme já explanado anteriormente, o objeto principal do presente trabalho possui como texto fundante, a Declaração de Cuzco de 2004. Este texto não chega a firmar novas estruturas no contexto de integração do subcontinente, mas sim, utiliza-se das estruturas já existentes - os blocos regionais CAN e Mercosul, o ACE no 59 na ALADI e o IIRSA - para criar um novo elemento de integração na América Latina: a Comunidade Sul-Americana de Nações.

Assim, com praticamente $80 \%$ das tarifas alfandegárias entre os países envolvidos em negociação nos próximos 15 anos, e com a construção de uma infraestrutura regional nos próximos 10 anos, fica possibilitada a criação consistente do terceiro maior bloco regional do mundo. Entretanto, para tal é necessária uma avaliação da sua conveniência e dos obstáculos a serem enfrentados.

Em relação à conveniência, o bloco é importante em primeiro lugar para o Brasil. Pois possibilita um acesso direto ao Oceano Pacífico via Bolívia-Peru e ao Caribe via Colômbia-Venezuela, um melhor controle da zona amazônica - abrangida pelo Tratado Amazônico -, e teria um acesso facilitado os recursos energéticos dos países vizinhos. Ainda, geopoliticamente o Brasil assumiria a posição central no bloco, devido ao seu tamanho territorial, contingente populacional e força econômica. ${ }^{15}$

O projeto é importante para a Comunidade Andina, pois possibilita uma real integração com o Mercosul ao invés da sua simples absorção pelo mesmo. Desta forma, abririam-se portas para um maior diálogo com a UE, e de negociações internas onde ela poderia se valer de seu peso de $13 \%$ da população e do PIB da América do Sul. ${ }^{16}$

Para os outros países do Mercosul (excetuando-se o Brasil), a CSN seria importante por proporcionar a incorporação plena do Chile no bloco regional, a possibilidade de ter uma maior influência geopolítica nos países ao norte da

${ }^{15}$ CARDONA. Diego C. ¿Tiene futuro la comunidad sudamericana de naciones?. Foreign Affairs En Español, Abr-Jun 2005. Disponível em: http://www.foreignaffairs-esp.org/. Acesso em: 22 de maio. de 2005.

${ }^{16}$ CARDONA. Diego C. ¿Tiene futuro la comunidad sudamericana de naciones?. Foreign Affairs En Español, Abr-Jun 2005. Disponível em: http://www.foreignaffairs-esp.org/. Acesso em: 22 de maio. de 2005. 
América do Sul, e, por fim, teriam maior força no cenário político internacional com o apoio da CAN. ${ }^{17}$

Ainda, haveria obviamente um incremento no comércio entre a CAN e o Mercosul. Os valores nas trocas comerciais entre os dois blocos giram em torno de 5,34 bilhões de dólares. ${ }^{18}$ Seguramente esse valor sofreria um acréscimo se houvesse mudanças na política alfandegária e comercial da região - fundadas no

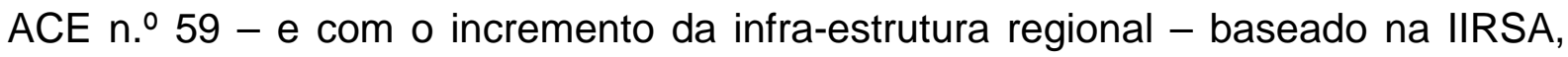
respectivamente.

O cenário internacional para a criação do bloco também se encontra favorável, uma vez que é observável uma queda da influência estadunidense na região devido ao fracasso das políticas econômicas neoliberais adotadas pelos governos sul-americanos no período pós-Consenso de Washington. E também, devido à ascensão de partidos de esquerda ao poder executivo destes países. Ainda, o surgimento de uma nova classe política, baseada nos movimentos sociais de luta por melhores condições de vida - indígenas no Equador, Peru e Bolívia; classe média e desempregados na Argentina - dá direção ao processo de integração regional. Por fim, ocorre o fortalecimento do capitalismo impulsionado pelo Estado, e o incremento das relações Sul-Sul devido à fragilidade das empresas de nações em desenvolvimento ante à competição com multinacionais do hemisfério norte. ${ }^{19}$

Contudo, existem diversos obstáculos concretos à integração sul-americana. Em primeiro lugar podemos citar a já mencionada tendência de alinhamento de certos países da CAN - principalmente Colômbia e Equador - com os EUA, em função da profunda participação econômica deste nos mercados da primeira. $^{20}$

Dentro do Mercosul - excetuando-se, neste momento, o Brasil; embora não haja a mesma tendência, há um certo ceticismo em relação à CSN, pois ela é vista

17 CARDONA. Diego C. ¿Tiene futuro la comunidad sudamericana de naciones?. Foreign Affairs En Español, Abr-Jun 2005. Disponível em: http://www.foreignaffairs-esp.org/. Acesso em: 22 de maio. de 2005.

${ }^{18}$ CAN. Intercambio Comercial Entre La Comunidad Andina Y Mercosur: 1994-2003 Disponível em: <http://www.comunidadeandina.org>. Acesso em 10 mar. 2005.

19 CHACÓN, José. Integración Sudamericana: un paso hacia el posneoliberalismo. Disponível em: http://www.ceicomobservatoriodelsur.org/ Acesso em: 23 de maio. de 2005.

20 "No obstante, muchos países andinos son favorables al proyecto estadounidense y el Mercosur no podrá disuadirlos de adherirse a él. Ante tal situación, Argentina y Brasil están proponiendo a los países andinos que se adhieran al ALCA, si les conviene, siempre que aseguren al Mercosur las mismas ventajas que concedan a Estados Unidos y reciban reciprocidad de parte del Mercosur. Creo, finalmente, que esa tendencia será la que prevalezca." JAGUARIBE, Hélio. El proyecto sudamericano. Foreign Affairs En Español, Abril-Junio 2005. Disponível em: http://www.foreignaffairs-esp.org/. Acesso em: 22 de maio. de 2005. 
com certa desconfiança - pelo Paraguai, Argentina e Uruguai - por ser temida como mais um projeto brasileiro de se fortalecer politicamente na região. Ainda, tais países temem que tal projeto desvirtue os objetivos essenciais do Mercosul, em função da busca de um mercado comum mais amplo.

Outro fator que figura como obstáculo à CSN é a real possibilidade de crescimento do comércio intragrupo, uma vez que ele é fundamental para a existência de um mercado comum. Em bases atuais essa modalidade comercial não atinge sequer $25 \%$ do comércio exterior dos países envolvidos.

Da mesma forma, constituem obstáculo os altos custos da integração da infra-estrutura - em função dos vários acordos financeiros que os Estados sulamericanos possuem com instituições multilaterais como o $\mathrm{FMI}$ - e os possíveis impactos ambientais que irá gerar.

A assimetria político-econômica entre os associados do bloco também é foco de críticas, e pela falta de estabilidade institucional de certos países, e pela dúvida da capacidade dos países mais desenvolvidos em suportar os custos pelo desenvolvimento das regiões mais desfavorecidas - como aconteceu com a Grécia e Portugal na União Européia.

Um fator fundamental à existência do mercado comum, é a construção de políticas macroeconômicas unificadas, que atualmente não existem de forma alguma na região, constituindo, desta forma, grave objeção à existência da CSN. Neste sentido, existem sérias dúvidas quanto à possibilidade dos países envolvidos dipensarem futuramente sua soberania na condução de suas políticas macroeconômicas, em prol de uma condução regional unificada. Por fim, é necessário que seja dada a devida importância aos componentes culturais de disputa intra-regionais que podem dificultar o apoio popular aos acordos. Ou seja, a histórica rivalidade entre determinados países da região tais como: Brasil-Argentina; Colômbia-Venezuela; Equador-Peru; Chile-Argentina; Bolívia - Chile etc. ${ }^{21}$

Todavia, ainda que os obstáculos existam e que sejam muitos, o sonho de uma construção contra-hegemônica na América do Sul que seja instrumento de união entre os seus povos, deve ser motivo de superação de qualquer oposição. A luta contra a dominação econômica dos países em desenvolvimento pelos seus

${ }^{21}$ CARDONA. Diego C. ¿Tiene futuro la comunidad sudamericana de naciones?. Foreign Affairs En Español, Abr-Jun 2005. Disponível em: http://www.foreignaffairs-esp.org/. Acesso em: 22 de maio. de 2005. 


\section{vizinhos do hemisfério norte deve guiar qualquer processo de integração e superar os interesses de estratos sociais específicos que controlam o poder político na maioria dos países de terceiro mundo:}

"Otra enseñanza que nos debe dejar este tipo de atteggiamento es que es necesario pasar de la exclusiva motivación comercial o económica a la motivación idealística; ya que ésta es la única que justificará las cesiones que habrán de hacerse en el largo plazo por parte de todos los participantes en el proyecto.".22

Assim, é necessária a busca de uma efetiva autonomia sul-americana, que fortaleça a luta de seus povos num contexto internacional por condições mínimas de vida e de existência digna. ${ }^{23}$

\section{BIBLIOGRAFIA}

ARAMBURU, Enrique J. Perspectiva histórica de la evolución del Mercosur en un una integración sudamericana. Disponível em: <http://www.ceicomobservatoriodelsur.org>. Acesso em: 23 de maio. de 2005.

CAN. Intercambio Comercial Entre La Comunidad Andina Y Mercosur: 1994-2003 Disponível em: <http://www.comunidadeandina.org>. Acesso em 10 mar. 2005.

CARDONA. Diego C. ¿Tiene futuro la comunidad sudamericana de naciones?. Foreign Affairs En Español, Abr-Jun 2005. Disponível em: <http://www.foreignaffairs-esp.org>. Acesso em: 22 de maio. de 2005.

CARVALHO, Guilherme. A estratégia de integração da infra-estrutura da América do Sul e o Governo Brasileiro. Disponível em: <http://www.fase.org.br>. Acesso em: 20 de maio. de 2005.

CHACÓN, José. Integración Sudamericana: un paso hacia el posneoliberalismo. Disponível em: <http://www.ceicomobservatoriodelsur.org>. Acesso em: 23 de maio. de 2005.

FURTADO, Celso. A economia latino-americana. São Paulo: Companhia Editora Nacional, 1976. p. 268.

22 ARAMBURU, Enrique J. Perspectiva histórica de la evolución del Mercosur en un una integración sudamericana. Disponível em: http://www.ceicomobservatoriodelsur.org/ Acesso em: 23 de maio. de 2005.

${ }^{23}$ Celso Furtado, neste sentido, já ressaltava a importância do projeto de integração latino-americana estar pautado numa política de desenvolvimento dos países envolvidos e evolução de suas estruturas políticas em prol de uma maior independência econômica externa: 'É de se esperar, contudo, que a chamada 'integração' econômica, hoje simples instrumento da política de desenvolvimento dos governos nacionais, ponha em marcha um processo evolutivo das estruturas, políticas, o que, por um lado, corresponde a uma exigência das relações internacionais. A necessidade de definir de uma forma mais realista as suas relações com os grandes pólos de poder do mundo atual, particularmente os EUA, está contribuindo para que os latino-americanos valorizem o que têm em comum e caminhem para a definição de um projeto regional que condicionará de forma cada vez mais perceptível a evolução sócio-política no plano nacional. FURTADO, Celso. A economia latino-americana. São Paulo: Companhia Editora Nacional, 1976, p. 268. 
GADEA, Rosario Santa. La Iniciativa IIRSA - El Reto de Integrar el Espacio Físico de América del Sur. Disponível em: <http://www.comunidadeandina.org>. Acesso em 10 mar. 2005.

GALEANO, Eduardo. As veias abertas da América Latina. 2. ed. RJ: Paz e Terra, 1978. p. 281.

GINESTA, Jacques. Los sistemas de integración a comienzos del siglo XXI. Disponível em: <http://www.amersur.org.ar>. Acesso em 13 de maio. de 2005.

JAGUARIBE, Hélio. El proyecto sudamericano. Foreign Affairs En Español, Abril-Junio 2005. Disponível em: <http://www.foreignaffairs-esp.org>. Acesso em: 22 de maio. de 2005.

MRE. Declaração de Cuzco sobre a Comunidade Sul-Americana de Nações. Disponível em: <http://www.mre.gov.br>. Acesso em 10 maio. 2005.

O ESTADO DE SP. Editorial: Acordo Mercosul-CAN. Disponível em: <http://www.estadao.com.br>. Acesso em 15 de maio. de 2005.

PAIM, Elisangela Soldatelli. Projeto milionário pode trazer graves prejuízos ambientais. Disponível em: <http://www.comciencia.br>. Acesso em 10 mar. 2005.

PAIVA, Paulo. Mercosul e andinos discutem acordo no começo de Outubro. Gazeta Mercantil, 12 de set. de 2002, p. A12.

WAGNER, Allan. "La Comunidad Sudamericana de Naciones: Un gran programa de desarrollo descentralizado". Disponível em: <http://www.comunidadeandina.org>. Acesso em 10 mar. 2005. 